OPEN ACCESS

Edited by:

Ram Gupta,

Pittsburg State University,

United States

Reviewed by:

Hitendra Kumar Malik,

Indian Institute of Technology

Delhi, India

Ho Won Jang,

Seoul National University, South Korea

*Correspondence:

Tae Gyu Kim

tgkim@pusan.ac.kr

Specialty section: This article was submitted to Thin Solid Films,

a section of the journal

Frontiers in Materials

Received: 17 February 2020 Accepted: 02 June 2020

Published: 07 July 2020

Citation:

Li W, Tan XY, Park YM, Shin DC, Kim DW and Kim TG (2020) Improved

Thermal Resistance and Electrical

Conductivity of a Boron-Doped DLC

Film Using RF-PECVD.

Front. Mater. 7:201.

doi: 10.3389/fmats.2020.00201

\section{Improved Thermal Resistance and Electrical Conductivity of a Boron-Doped DLC Film Using RF-PECVD}

\author{
Wanrong Li ${ }^{1}$, Xing Yan Tan ${ }^{1}$, Yeong Min Park ${ }^{1}$, Dong Chul Shin ${ }^{2}$, Dae Weon Kim ${ }^{3}$ and \\ Tae Gyu Kim ${ }^{4 *}$
}

${ }^{1}$ Department of Nano Fusion Technology, Pusan National University, Busan, South Korea, ${ }^{2}$ Department of Mechanical Engineering, Koje College, Geoje, South Korea, ${ }^{3}$ School of Intelligent Automobile Engineering, Silla University, Busan, South Korea, ${ }^{4}$ Department of Nanomechatronics Engineering, Pusan National University, Busan, South Korea

Diamond-like carbon (DLC) film doped with boron has unique properties and displays higher thermal resistance, lower internal stress, and better electrical conductivity than un-doped DLC film; this makes it is suitable for various applications, especially in outer space. Radio-frequency plasma-enhanced chemical vacuum deposition of boron-doped DLC film was performed to determine the optimal percentage of boron for improving thermal resistance. Additional heat treatment and 40 vol\% $\mathrm{B}_{2} \mathrm{H}_{6} / \mathrm{CH}_{4}$ yielded the best electrical conductivity. X-ray photoelectron spectroscopy, thermal gravimetric analysis, Raman spectroscopy, and the four-point probe method were utilized to analyze the properties of boron-doped DLC film. The boron-doped DLC film displayed outstanding performance in terms of thermal resistance and electrical conductivity.

Keywords: DLC, boron-doped, RF-PECVD, thermal treatment, electrical resistance

\section{INTRODUCTION}

Diamond-like carbon (DLC) has an amorphous crystalline structure and includes both $\mathrm{sp}^{3}$ (diamond-like) and $\mathrm{sp}^{2}$ (graphite-like) bonds. The ratio of these two types of bonds determine the crystalline properties and is sued to classify carbon materials (Lifshitz, 1999; Donnet and Erdemir, 2007). Conventional DLC has poor thermal resistance, leading to degradation of performance under high temperatures. At high temperatures, the $\mathrm{sp}^{3}$-bonds change to $\mathrm{sp}^{2}$-bonds, which influence the graphitization of DLC film (Robertson, 2002). DLC film is a metastable material under high stress. During heating and annealing, the structure of DLC film changes from diamond-like to graphite-like (Sánchez-López and Fernández, 2008). The thermal resistance of DLC films is usually poor, which limits their application in high temperature environments. The thermal resistance of DLC film is directly related to its physical characteristics and structure, chemical composition, and thickness. The addition of heterogeneous elements improves the overall properties of DLC films (Tallant et al., 1995). Research on boron-doped DLC films has mostly focused on their electrical properties. Usually, resistivity is measured in the range of $1 \times 10^{12}-1 \times 10^{16} \Omega / \mathrm{cm}$. Interestingly, the resistivity varies with the degree of deformation of the crystalline structure. It has been shown that doping with boron leads to graphitization (Kakiuchi et al., 2000), as well-improved 


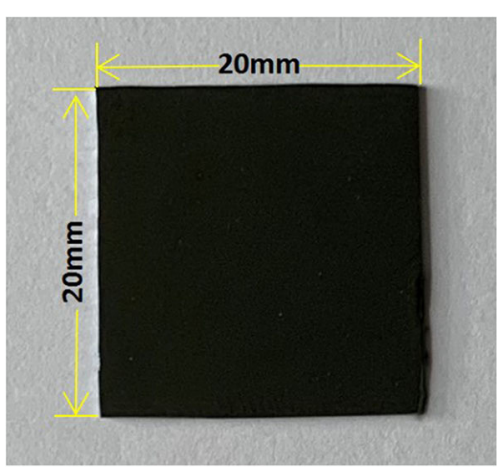

FIGURE 1 | Photograph of boron doped DLC coated on Si (1 0 0) substrate.

TABLE 1 | Pretreament conditions before DLC deposition.

\begin{tabular}{lccc}
\hline $\begin{array}{l}\text { Ar } \\
(\mathbf{s c c m})\end{array}$ & $\begin{array}{c}\text { RF Power } \\
\text { (W) }\end{array}$ & $\begin{array}{c}\text { Time } \\
(\mathbf{m i n})\end{array}$ & $\begin{array}{c}\text { Working pressure } \\
\text { (torr) }\end{array}$ \\
\hline 30 & 300 & 30 & $2.0 \times 10^{-2}$ \\
\hline
\end{tabular}

TABLE 2 | DLC film deposition conditions.

\begin{tabular}{lcccc}
\hline Sample & $\begin{array}{c}\mathbf{B}_{\mathbf{2}} \mathbf{H}_{\mathbf{6}} / \mathbf{C H}_{\mathbf{4}} \\
\mathbf{( \% )}\end{array}$ & $\begin{array}{c}\mathbf{R F} \text { power } \\
\mathbf{( W )}\end{array}$ & $\begin{array}{c}\text { Time } \\
\text { (hour) }\end{array}$ & $\begin{array}{c}\text { Working pressure } \\
\text { (torr) }\end{array}$ \\
\hline$\# 1$ & $0 \%$ & 300 & 1 & $2.0 \times 10^{-2}$ \\
$\# 2$ & $10 \%$ & 300 & 1 & $2.0 \times 10^{-2}$ \\
$\# 3$ & $20 \%$ & 300 & 1 & $2.0 \times 10^{-2}$ \\
$\# 4$ & $30 \%$ & 300 & 1 & $2.0 \times 10^{-2}$ \\
$\# 5$ & $40 \%$ & 300 & 1 & $2.0 \times 10^{-2}$
\end{tabular}

electrical conductivity and reduced internal stress, in DLC films such as used $\mathrm{Cu} / \mathrm{Ti}$ and OPT-DLC (Ahmad and Alsaad, 2007; Neeraj et al., 2012, 2013a). However, performance was not uniform among previous studies due to inconsistency in the deposition methods used. In space program, the utmost level of tribologic, thermal, and electrical characteristics have to require for long-time mission of solar cell's orientation, azimuth of antenna, gimbal adjustment of propulsions. The high performance of surface hardness but having conductivity to get rid of charging electrons in plasma circumstance on orbit is required, DLC treated electrical conductive, thermal resistive, and mechanical harness is expected the well-satisfied solution.

\section{EXPERIMENT}

The specimens in this study were (110) silicon wafers with dimensions of $20 \mathrm{~mm}(\mathrm{~W}) \times 20 \mathrm{~mm}(\mathrm{~L})$, as shown in Figure $\mathbf{1}$. First, ultrasonic cleaning was conducted for $30 \mathrm{~min}$, using $\mathrm{C}_{3} \mathrm{H}_{6} \mathrm{O}$ (acetone), $\mathrm{C}_{2} \mathrm{H}_{5} \mathrm{OH}$ (ethanol), and deionized (DI) water, to remove impurities on the surface. Radio-frequency plasmaenhanced chemical vapor deposition RF-PECVD of the DLC film was performed. The inside wall was checked to scavenge negative remnant and the plasma sourced by argon (Ar) gas was sustained for $30 \mathrm{~min}$, which induced a hot starting state, the operation of pre-cleaning gave the thermally stable circumstance in the chamber. The sample was pretreated to promote better adhesion on the surface of the DLC films, as shown in Table 1. Two gases, $\mathrm{CH}_{4}$ (methane) and $\mathrm{B}_{2} \mathrm{H}_{6}$ (diborane), were supplied under $0,10,20,30$, and $40 \mathrm{vol} \%$ conditions. The radio-frequency power supply was $300 \mathrm{~W}$, the operation time was $60 \mathrm{~min}$, and the pressure in the chamber was $2.0 \times 10^{-2}$ Torr. The sample coatings conditions are shown in Table 2.

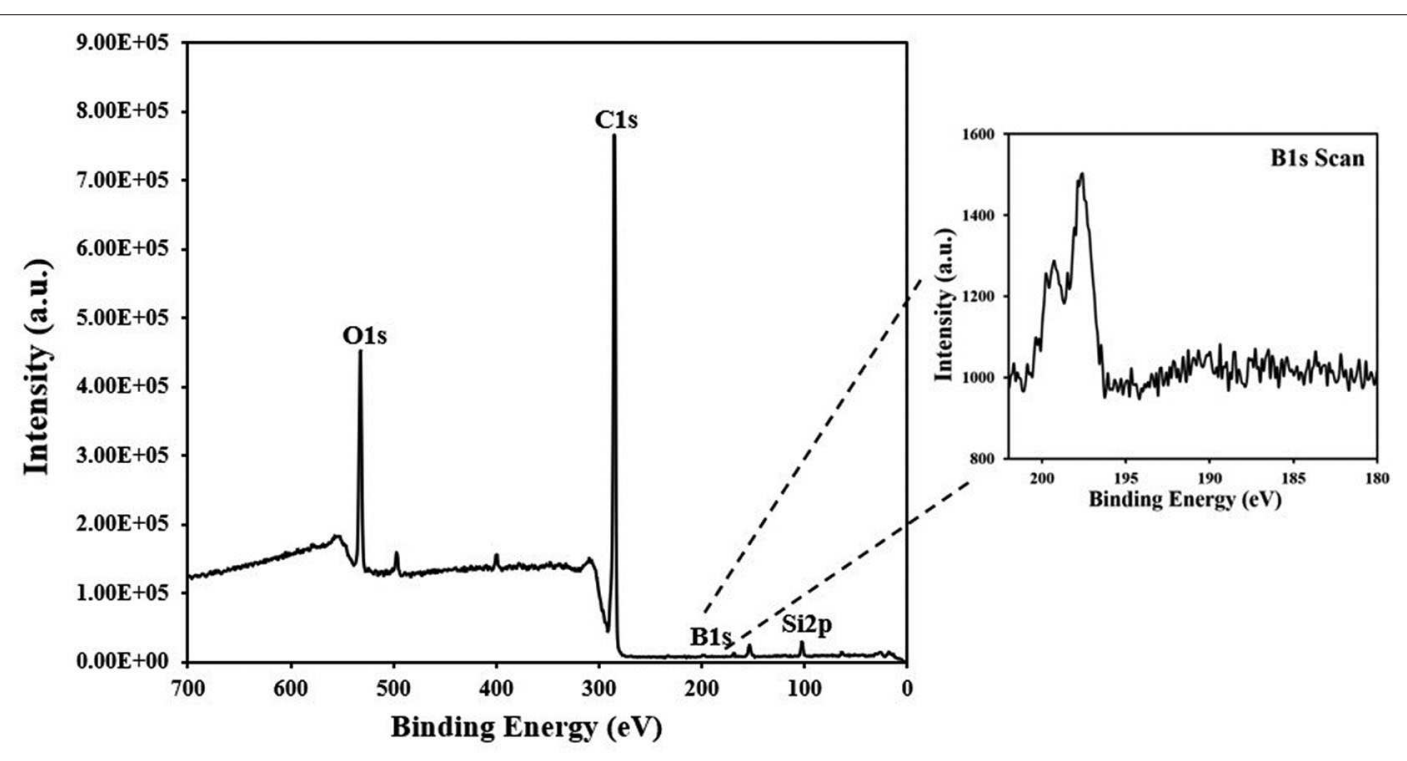

FIGURE 2 | XPS of boron doped DLC films. 


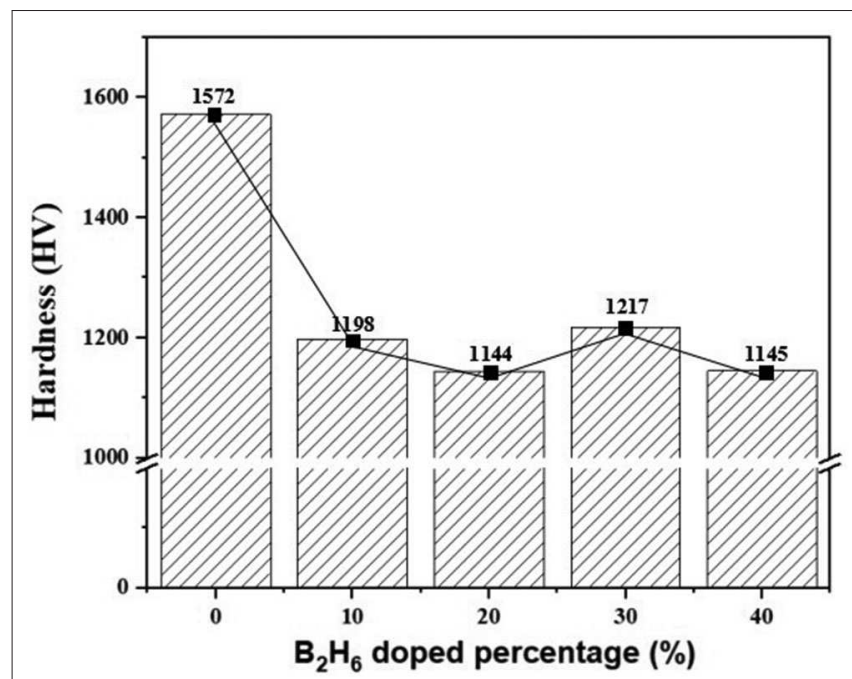

FIGURE 3 | Vickers hardness of un-doped DLC films and boron doped DLC films with different $\mathrm{B}_{2} \mathrm{H}_{6}$ doping percentage.

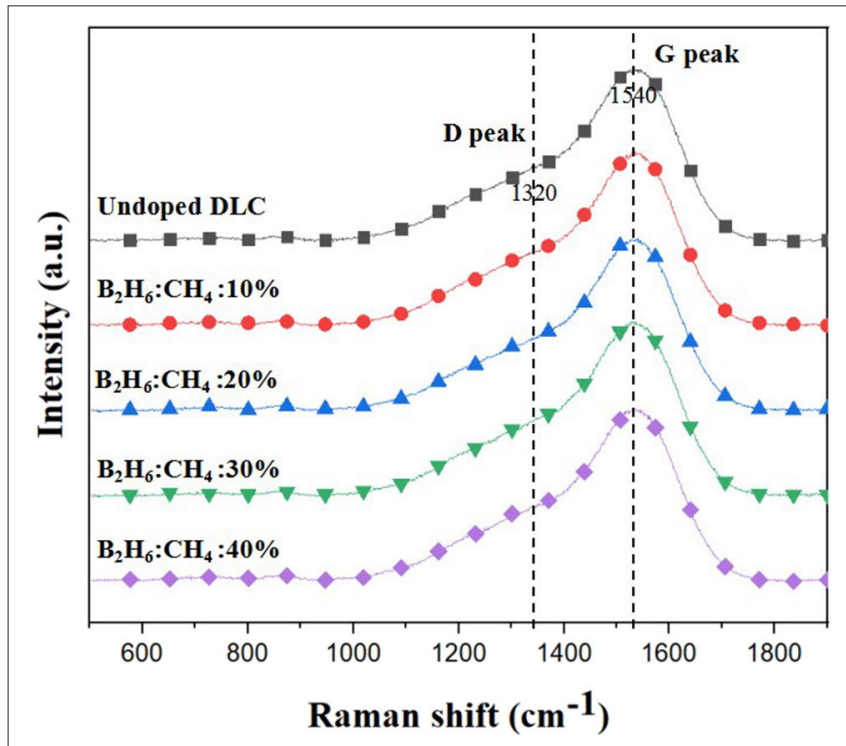

FIGURE 4 | Raman spectra of un-doped DLC films and boron doped DLC films with different $\mathrm{B}_{2} \mathrm{H}_{6}$ doped percentage.

TABLE 3 | Raman spectra results of the position of G peak, and FWHM of G peak and intensity ratio of the $D$ peak and $G$ peak.

\begin{tabular}{lcccc}
\hline Sample & $\mathbf{B}_{2} \mathbf{H}_{6} / \mathbf{C H}_{\mathbf{4}}$ & G peak & FWHM(G) & $\mathbf{I}_{\mathbf{D}} / \mathbf{I}_{\mathbf{G}}$ \\
\hline$\# 1$ & $0 \%$ & $1,545.51$ & 164.71 & 0.444 \\
$\# 2$ & $10 \%$ & $1,544.30$ & 171.57 & 0.518 \\
$\# 3$ & $20 \%$ & $1,542.86$ & 170.53 & 0.513 \\
$\# 4$ & $30 \%$ & $1,545.03$ & 172.07 & 0.522 \\
$\# 5$ & $40 \%$ & $1,544.98$ & 171.15 & 0.517
\end{tabular}

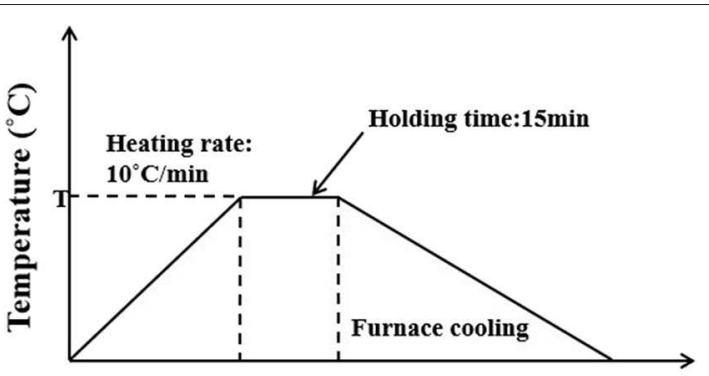

Time (min)

$\mathrm{T}=300^{\circ} \mathrm{C}, 350^{\circ} \mathrm{C}, 400^{\circ} \mathrm{C}$

FIGURE 5 | Heat treatment conditions in muffle furnace.

\section{RESULTS AND DISCUSSION}

Boron was doped into DLC film on Si substrate using $\mathrm{B}_{2} \mathrm{H}_{6}$. The state of the doped boron in the DLC film was analyzed using $\mathrm{X}$-ray photoelectron spectroscopy (XPS), as shown in Figure 2. Under $40 \mathrm{vol} \% \mathrm{~B}_{2} \mathrm{H}_{6} / \mathrm{CH}_{4}$, a peak of $\mathrm{B}_{1} \mathrm{~s}$ was detected in the range $196.38-199.68 \mathrm{eV}$. However, the peak $\mathrm{B}_{1} \mathrm{~s}$ intensity was weaker than that of other crystalline carbon materials, such as diamond; it is thought that $\mathrm{B}-\mathrm{C}$ or $\mathrm{B}-\mathrm{H}$ settle during the unstable bonding progress. During the deposition reaction of DLC in the plasma, C-C and C-H chains are more likely to react than $\mathrm{B}-\mathrm{C}$ and $\mathrm{B}-\mathrm{H}$. The binding force of boron is greater than that of carbon, but under low-deposition temperature process conditions, there is only enough energy for weak binding. To measure the thickness of the DLC film, and to determine the growth rate of the films deposited on the substrate, the Stylus Profiler instrument (Bruker) was used to measure the average growth rate at regular intervals. The growth rate of the borondoped film was $897.6 \mathrm{~nm} / \mathrm{h}$ under $\mathrm{B}_{2} \mathrm{H}_{6}$, while the growth rate of the un-doped film was $799.6 \mathrm{~nm} / \mathrm{h}$. Thus, boron doping increased film thickness. Hardness was tested with the nano-indenter. The maximum Vickers hardness was 1,572 HV for the un-doped DLC films, which was higher than that of the doped DLC films $(1,176.3$ HV; Figure 3). Structural stress is related with sp2 fraction of carbon, increase of $\mathrm{sp} 3 / \mathrm{sp} 2$ ratio determined improved hardness but reduced the electrical conductivity, strong bonding with nearest neighbor atoms of $\mathrm{sp} 3$ and less sp2 fractions shows high $\mathrm{H}$ values (Neeraj et al., 2011, 2013b). This result could be due to the aggregation of nanoclusters splitting $\mathrm{sp}^{2}$ and $\mathrm{sp}^{3}$, in turn affecting the crystalline structure of the DLC film and creating a boundary composed of $\mathrm{sp}^{2}$. Thus, doped boron reduced the influence of the $\mathrm{sp}^{3}$ chains. The Raman spectra showed an asymmetric peak at $1,100-1,700 \mathrm{~cm}^{-1}$, D-peak, diamond-like carbon marked on $1,320 \mathrm{~cm}^{-1}$, and G-peak, graphite-like marked on $1,540 \mathrm{~cm}^{-1}$ are distinguished with vertical lines as shown in Figure 4. As the amount of doped boron increased, the intensity ratio of the $D$ and $G$ peaks $\left(I_{D} / I_{G}\right.$ ratio) gradually increased; the full width at half maximum (FWHM) of the G peak also increased, as 


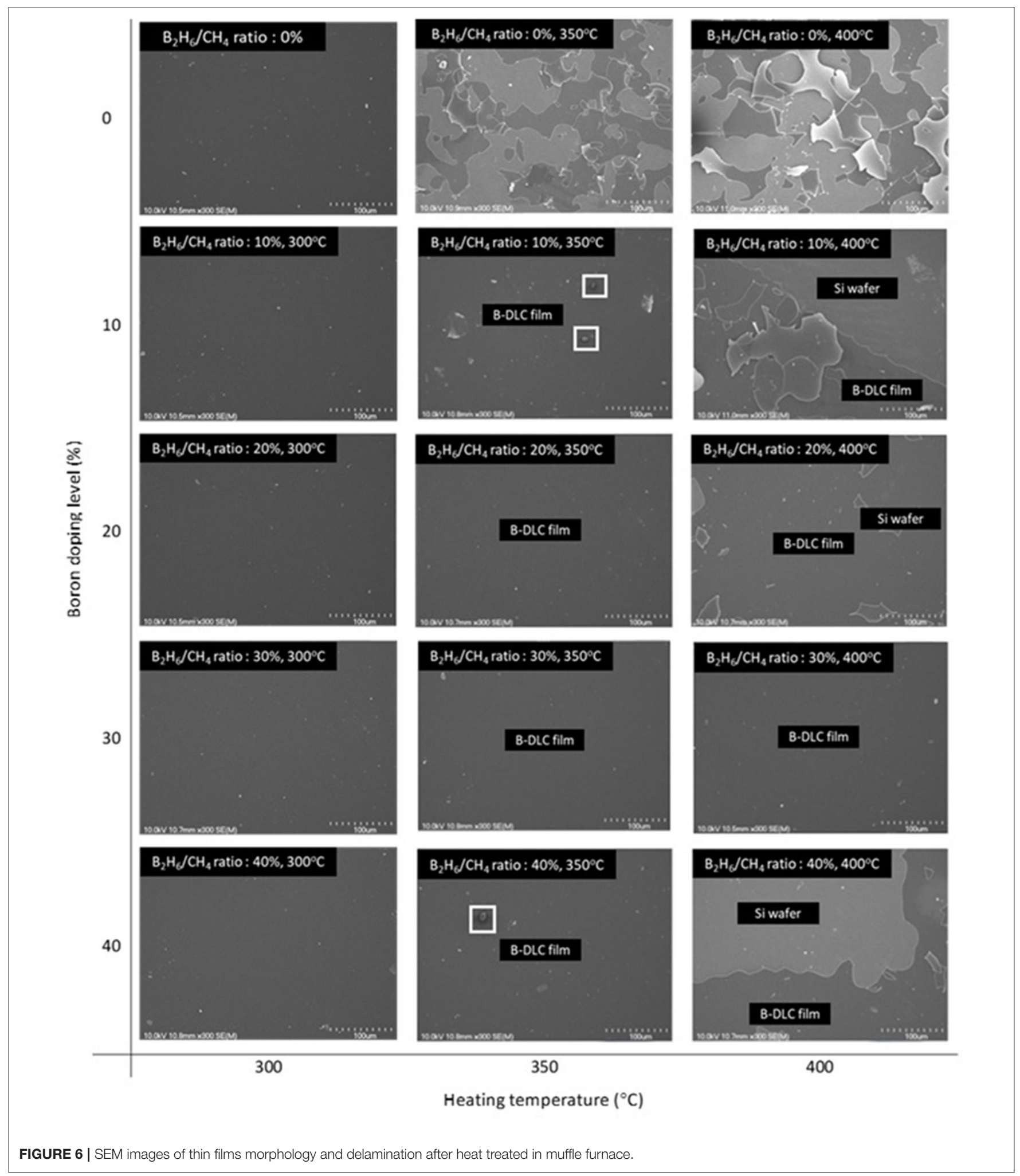

shown in Table 3 (Ferrari et al., 2002). In DLC films with an amorphous carbon structure, e.g., when diamond- and graphitelike networks are mixed together, boron controls the properties of the carbon network. Boron doping and heat treatment in DLC promote the formation of $\mathrm{sp}^{2}$ bonding. The active boron in doping progress interfere the normal combination of $\mathrm{sp} 3$ 


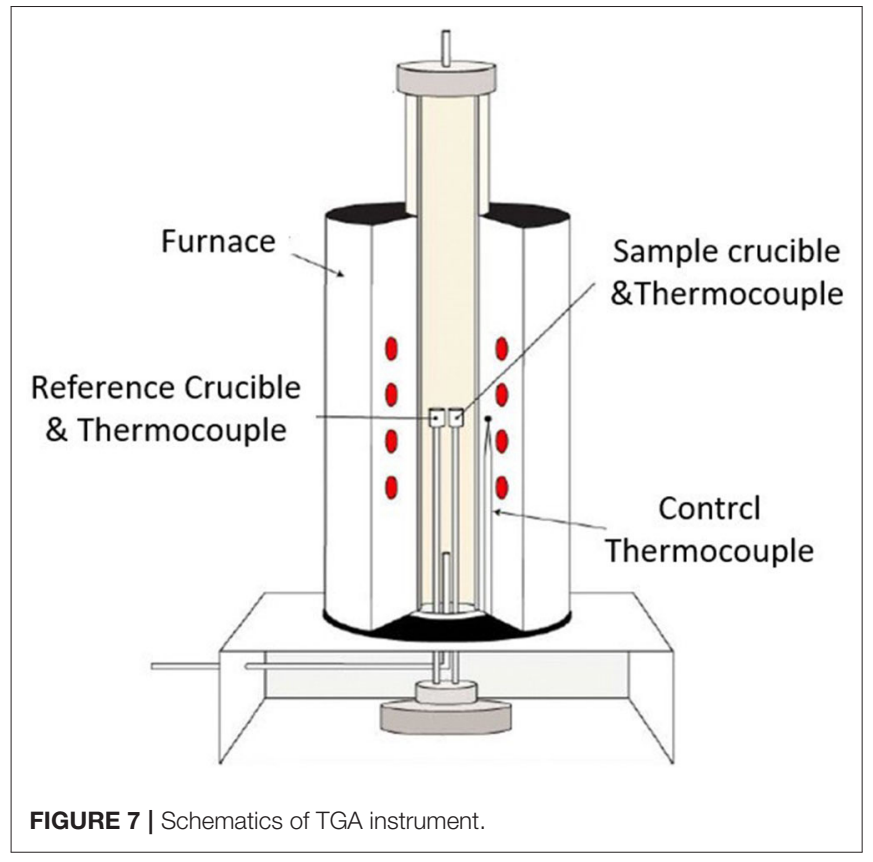

with the faster and lighter property in atomic characteristics and cause causes a split in the amorphous carbon structure, and the aggregation of $\mathrm{sp}^{3}$ induces a chain of $\mathrm{sp}^{2}$ carbon atoms. The change from an amorphous state to a pseudo-crystalline state, transited region between the amorphous formation and full crystal one, leads to yield the formation of graphite-like particles and to reduce the surface hardness. The $\mathrm{sp}^{3}$ bonds are fundamental to the properties of DLC films. In this study, the number of $\mathrm{sp}^{3}$ bonds in the DLC film was proportional to the hardness. High internal stress (in particular, compressive stress) in DLC films is associated with irregular $\mathrm{sp}^{3}$ bonds. The hardness of the DLC film also increases with increased internal stress and the results indicated that boron doping reduces internal stress in DLC films. A muffle furnace was utilized for heat treatment to evaluate the delamination of thin films when heated. As shown in Figure 5, the heating temperatures were 300,350 , and $400^{\circ} \mathrm{C}$ at a rate of $10^{\circ} \mathrm{C}$ per min with $15 \mathrm{~min}$ holding time. Then the specimens were let cooled at room conditions before removed from the furnace. Morphologies of the heat-treated samples were examined by using scanning electron microscope (SEM) as shown in Figure 6. All the thin films showed no changes or remained intact when heat-treated at $300^{\circ} \mathrm{C}$. However, the undoped-DLC thin films delaminated when the heating temperature was raised to $350^{\circ} \mathrm{C}$. On the other hand, 30 vol\% boron-doped DLC thin films remained intact at all heating conditions. The un-doped and boron-doped DLC films (under 30 vol\% $\mathrm{B}_{2} \mathrm{H}_{6}$ ) were subjected to thermal gravimetric analysis (TGA). Figure 7 shows the TGA instrument. The TGA curve of the DLC films was typical of single-stage decomposition. The TGA curve of un-doped boron DLC is shown in Figure 8A. Weight loss occurred at around $300^{\circ} \mathrm{C}$, and continued as the temperature increased. The TGA curve of the $30 \mathrm{vol} \%$ borondoped DLC films is shown in Figure 8B. Weight loss occurred
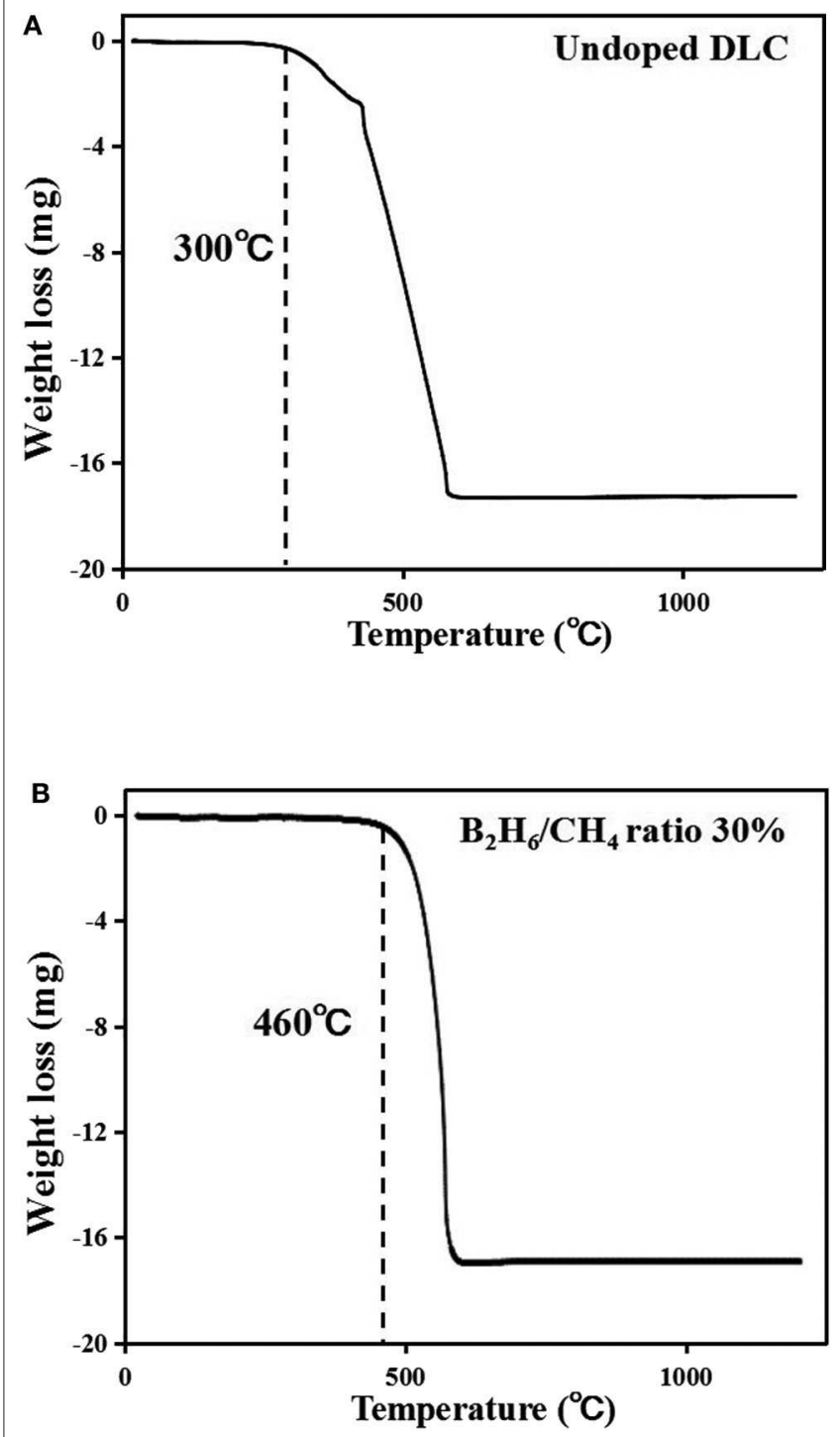

FIGURE 8 | TGA curve of (A) un-doped DLC films and (B) boron doped DLC films.

at around $460^{\circ} \mathrm{C}$. These results show the improved thermal resistance of the boron-doped DLC film. DLC films doped with 10 and 40 vol\% boron exhibited shedding phenomenon and cracks were found on their surfaces. The DLC films doped with 20 vol $\% \mathrm{~B}_{2} \mathrm{H}_{6}$ showed partial cracking on the surface. The DLC films doped with 30 vol\% $\mathrm{B}_{2} \mathrm{H}_{6}$ exhibited an intact surface under all thermal treatments. Among the boron-doped DLC films, the 30 vol\%-boron-doped films showed the highest thermal resistance. The four-point probe method was used to determine the electrical conductivity of the boron-doped DLC films. The films doped with 40 vol\% $\mathrm{B}_{2} \mathrm{H}_{6}$ had the highest electrical conductivity, as shown in Figure 9. Increasing the boron concentration improved the electrical conductivity and reduced sheet resistance. The DLC films doped with 30 vol\% $\mathrm{B}_{2} \mathrm{H}_{6}$ demonstrated the worst 


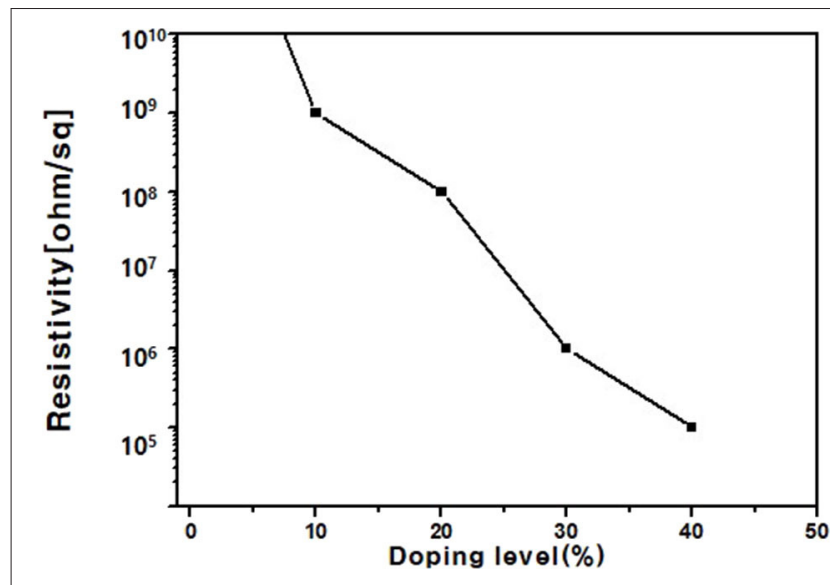

FIGURE 9 | Electrical resistance of as-deposited DLC films at different boron doping level.

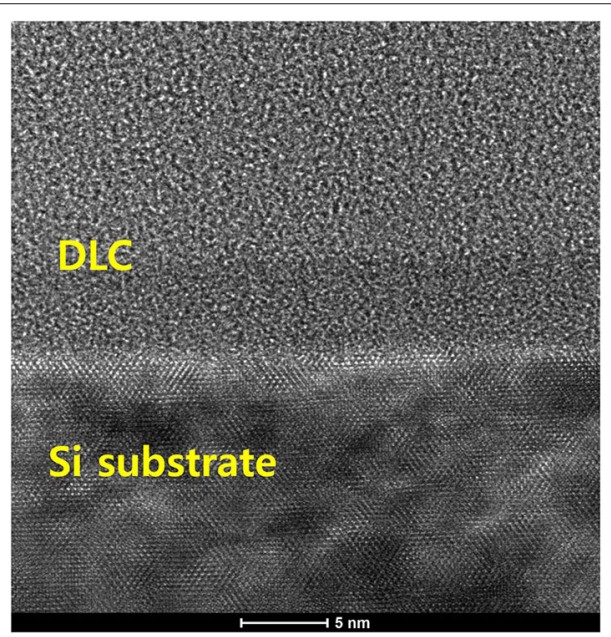

FIGURE 10 | Cross-sectional view by TEM image.

performance, irrespective of the heat treatment applied; this was attributed to saturation of $\mathrm{sp}^{3}$ and an accumulation of free electrons due to the action of boron inside the carbon structure. An electronic transport model was used to evaluate the relationship between DLC film conductivity and temperature, as show below:

$$
\sigma_{\mathrm{DC}(\mathrm{T})}=\sigma_{0} \exp \left[-\mathrm{E}_{\mathrm{act}} /(\mathrm{kT})\right]
$$

Where $\mathrm{k}$ is the Boltzmann constant, $\ln \sigma_{\mathrm{DC}} \sim 1 / \mathrm{T}$ is a straight line, $E_{a c t}$ is the activation energy, and $E_{a c t} / k$ is the slope of the curve, showing the relationship between conductivity and temperature. The heat activation mechanism depends on the carriers generated in the expanded state, which are near the Fermi level. When excited by heat, electrons jump through the Fermi gap. It has been reported that DLC films have a network that promotes confinement, and thus accumulation, of electrons. However, when thermal energy is supplied, excited electrons may demonstrate tunneling behavior, as seen in semiconductors. It has also been reported that a weak p-type dopant can form in DLC films under certain conditions; therefore, it is possible to obtain p-type semiconducting DLC films by doping them with boron (Al Mamun et al., 2018). For n-type semiconductors, $\mathrm{E}_{\mathrm{act}}$ $=\mathrm{E}_{\mathrm{C}}-\mathrm{E}_{\mathrm{F}}$, while for p-type semiconductors, $\mathrm{E}_{\mathrm{act}}=\mathrm{E}_{\mathrm{F}}-\mathrm{E}_{\mathrm{V}}$, where $\mathrm{E}_{\mathrm{F}}$ is the energy level, $\mathrm{E}_{\mathrm{C}}$ is the leading band mobility edge, and $\mathrm{E}_{\mathrm{V}}$ is the valence band mobility edge (Ma and Liu, 2001; Godet, 2002). The conductivity of DLC films depends on its $\mathrm{sp}^{2}$ bonds and the extent of doping. In this study, improved electrical conductivity of DLC films was achieved through boron doping, which enabled formation of a p-type dopant and an increase in $\mathrm{sp}^{2}$ bonds (Wei and Hing, 2002). The surface of DLC films was visualized under SEM and no significant difference was seen between the amorphous and pseudo-crystalline structure. Finally it was applied the TEM, Cscorrected TEM (Themis Z, FEI, USA), locared in Korea Institute of Ceramic Engineering and Technology (KICET) for finding the cross-sectional substantial view (Takanori et al., 2009) of crystal or atomic structure of B-DLC where also includes carbon crystal of sp2 and sp3. The amorphous crystal of B-DLC on upper layer and obvious crystal of 110-oriented Si substrate on lower layer as shown on Figure 10. A deposition method was proposed, as shown in Figure 11, and the results indicated that boron-doped DLC film included C-C, C-H, B-C, and B$\mathrm{H}$ chains and an amorphous carbon network; there were signs of electron tunneling and formation of a boundary area led to clustering formation. Additionally, some of the $\mathrm{B}_{2} \mathrm{H}_{6}$ and $\mathrm{CH}_{4}$ gas escaped under the low-temperature conditions, which resulted in the rare phenomenon of linkage of boron with $\mathrm{C}-\mathrm{C}$ and $\mathrm{C}-\mathrm{H}$.

\section{CONCLUSION}

A DLC film was deposited on Si substrate by RF-PECVD and born-doped using $10,20,30$, or 40 vol $\% \mathrm{~B}_{2} \mathrm{H}_{6}$. The deposition rate of the boron-doped DLC film was higher than that of the un-doped DLC film. The hardness of, and amount of $\mathrm{sp}^{3}$ bonds in, the boron-doped DLC films were lower than those for the un-doped film. Boron doping reduced the internal stress due to a reduction in the $\mathrm{sp}^{3}$ network, which improved thermal resistance up to a temperature of $460^{\circ} \mathrm{C}$, as shown by TGA; meanwhile, the 30 vol\% boron doped DLC films exceled in all heating condition whereas the un-doped DLC film only showed thermal resistance up to $300^{\circ} \mathrm{C}$. The undoped DLC films had the worst electrical conductivity under all heat treatments whereby 40 vol\% boron doped DLC films dramatically improved the electrical conductivity. It is possible to obtain p-type semiconducting DLC films by boron doping. As the temperature increased, more $\mathrm{sp}^{2}$ bonds developed, leading to an increase of clustering. This study shows that boron-doped DLC films may have applications in outer spacerelated projects. 


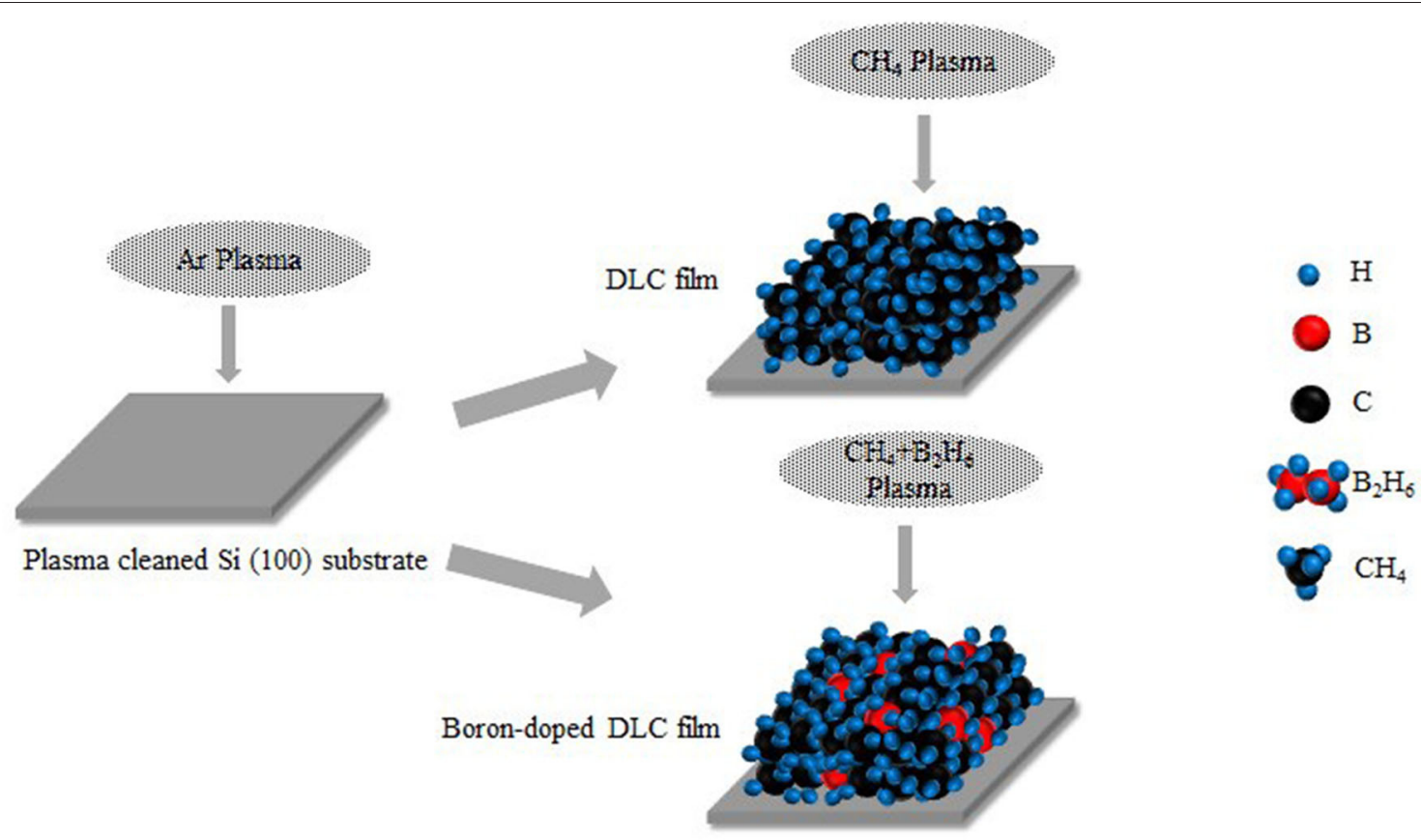

FIGURE 11 | Hypothetical schematic of boron doped DLC deposition process.

\section{DATA AVAILABILITY STATEMENT}

All datasets generated for this study are included in the article/supplementary material.

\section{AUTHOR CONTRIBUTIONS}

WL, YP, and TK: contributed conception and design of the study. DS and DK: organized the database. WL, DS, and DK: performed the statistical analysis. WL and XT: wrote the first draft of the

\section{REFERENCES}

Ahmad, A. A., and Alsaad, A. M. (2007). Adhesive B-doped DLC films on biomedical alloys used for bone fixation. Bull. Mater. Sci. 30, 301-308. doi: 10.1007/s12034-007-0050-5

Al Mamun, M. A., Furuta, H., and Hatta, A. (2018). Pulsed DC plasma CVD system for the deposition of DLC films. Mater. Today Commun. 14, 40-46. doi: 10.1016/j.mtcomm.2017.12.008

Donnet, C., and Erdemir, A. (eds.). (2007). Tribology of Diamond-Like Carbon Films: Fundamentals and Applications. Boston, MA: Springer Science \& Business Media. doi: 10.1007/978-0-387-49891-1

Ferrari, A. C., Rodii, S. E., Robertson, J., and Milne, W. I. (2002). Is stress necessary to stabilise sp3 bonding in diamond-like carbon? Diamond Relat. Mater. 11, 994-999. doi: 10.1016/S0925-9635(01)00705-1

Godet, C. (2002). Variable range hopping revisited: the case of an exponential distribution of localized states. J. Non-Crystal. Solids 299, 333-338. doi: 10.1016/S0022-3093(01)01008-0

Kakiuchi, H., Kobayashi, T., and Terai, T. (2000): Property change of diamondlike carbon thin films due to ion implantation. Nuclear Instruments manuscript. WL and XT: wrote sections of the manuscript. All authors contributed to manuscript revision, read, and approved the submitted version.

\section{FUNDING}

This research was supported by Basic Science Research Program through the National Research Foundation of Korea (NRF) funded by the Ministry of Education (grant no. 2018R1D1A1B07046366).
Methods Phys. Res. Section B: Beam Interact. Mater. Atoms 166, 415-419. doi: 10.1016/S0168-583X(99)01056-3

Lifshitz, Y. (1999). Diamond-like carbon-present status. Diamond Related Mater. 8, 1659-1676. doi: 10.1016/S0925-9635(99)00087-4

Ma, Z. Q., and Liu, B. X. (2001). Boron-doped diamond-like amorphous carbon as photovoltaic films in solar cell. Solar Energy Mater. Solar Cells 69, 339-344. doi: 10.1016/S0927-0248(00)00400-1

Neeraj, D., Kumar, S., and Malik, H. (2013b). Strange hardness characteristic of hydrogenated diamond-like carbon thin film by plasma enhanced chemical vapor deposition process Appl. Phys. Lett.102:011917. doi: 10.1063/1.47 75372

Neeraj, D., Kumar, S., and Malik, H. K. (2013a). Role of base pressure on the structural and nano-mechanical properties of metal/diamond-like carbon bilayers. Appl. Surface Sci. 274, 282-287. doi: 10.1016/j.apsusc.2013.03.037

Neeraj, D., Kumar, S., Malik, H. K., Govind., Rauthan, C. M. S., and Panwar, O. S. (2011). Correlation of sp3 and sp2 fraction of carbon with electrical, optical and nano-mechanical properties of argon-diluted diamondlike carbon films Appl. Surface Sci. 257, 6804-6810. doi: 10.1016/j.apsusc.2011. 02.134 
Neeraj, D., Kumar, S., Singh, S., and Malik, H. K. (2012). Oxygen modified diamond-like carbon as window layer for amorphous silicon solar cells. Solar Energy 86, 220-230. doi: 10.1016/j.solener.2011.09.025

Robertson, J. (2002). Diamond-like amorphous carbon. Mater. Sci. Eng. R: Rep. 37, 129-281. doi: 10.1016/S0927-796X(02)00005-0

Sánchez-López, J. C., and Fernández, A. (2008). Doping and Alloying Effects on DLC Coatings. Tribology of Diamond-Like Carbon Films. (Boston, MA: Springer), 311-338. doi: 10.1007/978-0-387-498 91-1_12

Takanori, T., Komiyama, T., Miki, H., Takagi, T., and Aoyama, T. (2009). XPS and TEM study of W-DLC/DLC double-layered film Thin Solid Films 517, 5010-5013. doi: 10.1016/j.tsf.2009.03.033

Tallant, D. R., Parmeter, J. E., Siegal, M. P., and Simpson, R. L. (1995). The thermal stability of diamond-like carbon. Diamond Rel. Mater. 4, 191-199. doi: 10.1016/0925-9635(94)00243-6
Wei, J., and Hing, P. (2002). Electrical properties of reactively sputtered carbon nitride films. Thin Solid Films 410, 21-27. doi: 10.1016/S0040-6090(02)00243-2

Conflict of Interest: The authors declare that the research was conducted in the absence of any commercial or financial relationships that could be construed as a potential conflict of interest.

Copyright (c) 2020 Li, Tan, Park, Shin, Kim and Kim. This is an open-access article distributed under the terms of the Creative Commons Attribution License (CC BY). The use, distribution or reproduction in other forums is permitted, provided the original author(s) and the copyright owner(s) are credited and that the original publication in this journal is cited, in accordance with accepted academic practice. No use, distribution or reproduction is permitted which does not comply with these terms. 